\title{
USING A SILICA SUBSTRATE TO MONITOR THE EFFECTIVENESS OF RADIOCARBON PRETREATMENT
}

\author{
M W Dee ${ }^{1}$ F Brock $•$ A D Bowles $•$ C Bronk Ramsey \\ Oxford Radiocarbon Accelerator Unit (ORAU), Research Laboratory for Archaeology and the History of Art (RLAHA), Uni- \\ versity of Oxford, Dyson Perrins Building, South Parks Road, Oxford OX1 3QY, United Kingdom.
}

\begin{abstract}
The objective of radiocarbon pretreatment is to eliminate any contaminant carbon from the sample material. Solvent washes and acid-base-acid (ABA) procedures are widely used for this purpose. However, quantitatively analyzing their effectiveness is surprisingly problematic, as it often requires large numbers of ${ }^{14} \mathrm{C}$ measurements or high-precision compositional analysis. The technique presented here involves monitoring the impact of different forms of contamination by measuring their adherence to a non-carbonaceous substrate called Chromosorb ${ }^{\circledR}$. Firstly, the substrate was used in place of a ${ }^{14} \mathrm{C}$ sample in order to monitor the accrual of carbon contamination during a standard solvent wash and ABA pretreatment. This produced a contamination profile against which modifications to the pretreatment procedure could be compared. Secondly, stocks were prepared of Chromosorb that had been infused with environmental contaminants and with common glues, adhesives, and preservatives. By monitoring the elimination of carbon from these stocks, the effectiveness of different pretreatment procedures could be evaluated and the most problematic of the contaminants for ${ }^{14} \mathrm{C}$ dating could be identified.
\end{abstract}

\section{INTRODUCTION}

Contamination is one of the main causes of inaccurate radiocarbon $\left({ }^{14} \mathrm{C}\right)$ dates. It occurs wherever the sample being analyzed has been incompletely purified of exogenous carbon. The severity of the problem is dependent on the amount of contamination present and the difference in ${ }^{14} \mathrm{C}$ age between the contaminant and the sample. The relationship may be expressed as follows:

$$
\mathrm{F}^{14} \mathrm{C}_{\text {measured }}=(1-\alpha) \mathrm{F}^{14} \mathrm{C}_{\text {sample }}+\alpha \mathrm{F}^{14} \mathrm{C}_{\text {contaminant }}
$$

where $\alpha=$ proportion of contamination in the extract being dated, and $\mathrm{F}^{14} \mathrm{C}=$ fraction of modern carbon.

Cases where large amounts of contamination are present are often obvious prior to pretreatment, or quickly become apparent during its application. However, the situation is more challenging when only a small amount of contamination is present but it still substantially affects the date obtained. This can occur if the ${ }^{14} \mathrm{C}$ age of the contaminant is considerably different from that of the sample. One of the worst scenarios arises when contaminants rich in ${ }^{14} \mathrm{C}$ are present in samples tens of thousands of years old. For example, if a sample is $20,000 \mathrm{BP}$ in age, but $10 \%$ of the dating extract consists of a contaminant that is $100 \%$ modern, then the final date estimate would be $\sim 14,000 \mathrm{BP}$. The opposite situation can also be severe, even though the distortion is linear in nature. That is, if a dating extract contains $10 \%$ depleted carbon contamination, then the date will be too old by $846 \mathrm{yr}$, regardless of the sample's true age.

The principal pathways by which contamination occurs can be defined as either natural or anthropogenic. Natural contamination usually arises during deposition, where exogenous compounds infiltrate the sample to be dated and become physically or chemically bound to it. The most common contaminants introduced in this way are bicarbonates from dissolved carbonate rock, and organic compounds produced by the microbial decomposition of plant and animal tissues, such as humic acids (Gowlett 1987; van Klinken and Hedges 1998).

Anthropogenic contamination results from the handling and modification of objects, either during antiquity or in modern times - such as during pretreatment in the laboratory. The term pretreatment refers to all the physical and chemical steps that are taken to eliminate contamination from the sam-

\footnotetext{
${ }^{1}$ Corresponding author. Email: michael.dee@rlaha.ox.ac.uk.
} 
ple being analyzed. The basic approach is to extract from the bulk sample an indigenous fraction that is likely to have remained chemically unmodified during deposition. However, throughout the laboratory procedure, care must be taken not to irreversibly add carbon-containing compounds to the sample material. The chemical pretreatment process usually comprises a series of steps, each designed to eliminate a potentially exogenous fraction. The most common approach is known as the ABA (acid-base-acid) method (de Vries and Barendsen 1954), which is also sometimes referred to as AAA or acid-alkali-acid. The initial acid step is employed to remove inorganic compounds, such as carbonates, and the base phase to dissolve humic acids (Green 1963; Hoper et al. 1998; van Klinken and Hedges 1998). However, by applying a base wash, most commonly sodium or potassium hydroxide, the incorporation of atmospheric $\mathrm{CO}_{2}$ is also promoted, thus risking contamination by modern carbon. This effect can be avoided by conducting the step in an inert gas environment, such as nitrogen. Otherwise, to ensure all such contamination is removed, it is imperative that an extra acid rinse is carried out immediately after the base phase.

In some cases, anthropogenic contamination may be the result of deliberate intervention, such as the application of glues and preservatives to the item selected for dating. Moreover, some glues are composed of exactly the same biopolymers as those sought by ${ }^{14} \mathrm{C}$ pretreatment, namely collagen and cellulose. An example of the former is pearl glue, used in woodworking, and the latter, methylcellulose, a glue traditionally employed for book repair. Contamination of this form is likely to pass undetected into the fraction obtained for dating. If contamination from glues and preservatives is suspected at the outset, additional treatments may be applied prior to the ABA procedure. One approach is a solvent wash that is aimed at removing non-polar additives, such as paraffin or beeswax. Clearly, if such solvents are carbon-containing they must be allowed sufficient time to completely evaporate before proceeding to the aqueous phases of the pretreatment procedure.

Testing the general effectiveness of ${ }^{14} \mathrm{C}$ pretreatment is surprisingly difficult. This type of analysis is different from routine monitoring of individual samples. Clearly, the purity of every dated fraction can be checked using a number of different parameters, such as $\delta^{13} \mathrm{C}$ values, or $\mathrm{C}: \mathrm{N}$ ratios of collagen samples (see van Klinken and Hedges 1998). But designing an experimental methodology to investigate the effectiveness of pretreatment chemistry in general is more problematic. The difficulty arises because of the variety of materials selected for dating, the challenge of detecting small quantities of contamination, and the necessity for any solution to be economically viable. The 2 basic approaches to the problem are either to measure the increase in purity of the underlying substrate or to measure the reduction in concentration of contaminant. The first approach often uses a known-age material as the substrate, such as dendrochronologically dated wood (e.g. Bruhn et al. 2001). In this case, the material is pretreated using different protocols or, where a specific impurity is being examined, deliberately contaminated and then pretreated. By dating the resultant product, the best pretreatment method can be determined. The disadvantages of this approach are largely economic. As a result of the statistical scatter of ${ }^{14} \mathrm{C}$ measurements, in order to differentiate the performance of different pretreatment techniques large numbers of ${ }^{14} \mathrm{C}$ dates are often required. Furthermore, as pretreatment protocols are constantly being improved, and the range of potential contaminants is essentially unlimited, this approach is often impractical. In some cases, where less sensitivity is required, the purity of the substrate may be determined on the basis of mass and not ${ }^{14} \mathrm{C}$ measurement, thereby saving significant expense. However, such rudimentary approaches are highly compromised by the imperfect replication of contamination from one test to the next, and the inevitable loss of substrate during pretreatment.

The second approach utilizes high-precision compositional analysis to monitor the concentration of the contaminant. A wide variety of spectroscopic techniques are used to determine the presence of 
impurities in ${ }^{14} \mathrm{C}$ samples, from FTIR analysis of bone and charcoal (for example, see Yizhaq et al. 2005; D'Elia et al. 2007) to X-ray diffraction of shells (see Goslar and Pazdur 1985; Yates 1986). Indeed, this area continues to be the subject of much research, and the effectiveness of each approach is not reviewed here. Nonetheless, in addition to the obvious limitation of requiring specialist equipment, such approaches are generally case-specific. That is, they usually relate to specific forms of contamination associated with specific sample types. For instance, no such technique could be applied in a general manner to verify that alterations to laboratory protocols do not inadvertently introduce new forms of carbon contamination.

\section{OBJECTIVES}

The aim of the method presented here was to develop an effective, versatile, and inexpensive means of monitoring and assessing the effectiveness of ${ }^{14} \mathrm{C}$ pretreatment. An inert silica material called Chromosorb $^{\circledR}$ (W/AW, Mesh Size 30-60, Phase Separations Ltd, UK) was adopted as the substrate. In this way, any variation in the level of carbon present could be attributed to contamination. Further, such variation could be detected with great precision by a mass spectrometer, commonly available to ${ }^{14} \mathrm{C}$ laboratories. A working assumption was that the silica substrate's affinity for carbon contamination was comparable to that of a "typical" sample material. This assumption was supported by 2 different considerations. Firstly, ${ }^{14} \mathrm{C}$ samples show such a variety of surface qualities that no one material could be said to be the most "typical." Secondly, Chromosorb's large surface area meant it was likely to be at least as absorbent as most ${ }^{14} \mathrm{C}$ samples. However, it is acknowledged that this approach is not an ideal model for cases where chemical cross-linking has occurred between the sample and the contaminant.

The first step involved establishing the background level of contamination accrued during pretreatment. This was then used as a reference profile, against which the effect of any modifications could be compared, such as an increase in hydroxide concentration, or a change in the temperature settings employed. The second objective was to determine the efficiency with which common environmental contaminants and conservation products were removed, which allowed for the relevant pretreatment procedures to be optimized.

\section{METHODS}

\section{Contamination Accrual}

The first set of contamination accrual experiments focused on the organic solvent treatments. Proxy ${ }^{14} \mathrm{C}$ samples, consisting of 20-mg amounts of Chromosorb, were prepared in a series of test tubes, which had been baked out at $500{ }^{\circ} \mathrm{C}$ for $1 \mathrm{hr}$ to remove any residual carbon. The samples were then subjected to Oxford Radiocarbon Accelerator Unit's (ORAU) standard solvent wash for cases where non-polar additives were suspected, but their exact nature was not known. Specifically, this entailed: acetone $\left(45^{\circ} \mathrm{C}, 45 \mathrm{~min}\right)$, methanol $\left(45^{\circ} \mathrm{C}, 45 \mathrm{~min}\right.$ ), and chloroform (room temperature, $45 \mathrm{~min}$ ). After each stage of the process, 2 test tubes were removed and their contents left to dry overnight in a fumehood. The carbon content on the silica substrate was then detected by combusting 10-mg quantities in an elemental analyzer coupled to a mass spectrometer (see Brock et al. 2010 for details of ORAU procedures). Once the basic profile of contamination accrued in this manner had been established, the effect of changing the temperature and time settings was also examined.

In the next series of experiments, Chromosorb samples were subjected to the $\mathrm{ABA}$ pretreatment process used at ORAU. Briefly, this entailed acid $\left(1 \mathrm{M} \mathrm{HCl}, 80^{\circ} \mathrm{C}, 20 \mathrm{~min}\right)$, base $\left(0.2 \mathrm{M} \mathrm{NaOH}, 80^{\circ} \mathrm{C}\right.$, $20 \mathrm{~min}$ ), and acid ( $\left.1 \mathrm{M} \mathrm{HCl}, 80^{\circ} \mathrm{C}, 20 \mathrm{~min}\right)$. After each of the 3 main steps, a rinse was thrice per- 
formed using ultrapure water. As previously, after each step in the process, 2 test tubes were removed, but this time their contents were freeze-dried. The quantity of residual carbon was determined by combusting 10-mg quantities, as above. Similarly, the effect of altering reaction parameters, particularly of the base phase, was also investigated.

\section{Contamination Removal}

Once the pattern of contamination accrual had been determined, a collection of experiments was undertaken to analyze the effectiveness of pretreatment on contaminated Chromosorb. Stocks were prepared of Chromosorb mixed with common environmental and anthropogenic contaminants. The former included humic acid (Fluka Chemika), and groundwater carbonates infused by way of the hardwater effect; that is, by the evaporation of mains supply water from a vessel containing Chromosorb. In general, the anthropogenic contaminants tested were substances commonly used for conservation (see Table 1), including preservatives and fixatives obtained from both natural products (glues) and by artificial synthesis (adhesives). All were available commercially, except natural bitumen, which was obtained from the Ironbridge Gorge Museum, Shropshire.

In order to aid curing, the glue and adhesive stocks were artificially aged. A schematic of the apparatus used for this purpose is shown in Figure 1. The primary objective was to maintain elevated temperature $\left(60^{\circ} \mathrm{C}\right.$ ) and $100 \%$ humidity (D Howell, personal communication; Green and Thickett 1995). The stocks, and 1 uncontaminated control sample, were kept under the conditions shown for a period of 1 month.

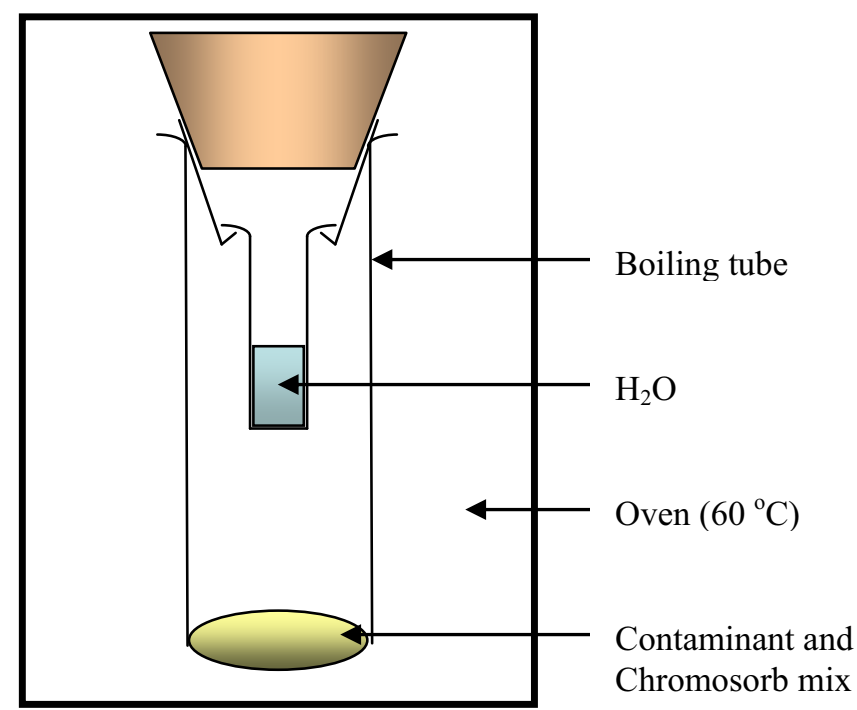

Figure 1 The apparatus used to artificially age the adhesives and glues. The mixtures were kept as indicated for 1 month.

The original ratio of contaminant to Chromosorb (1:4) was kept approximately constant for all of the glue and adhesive stocks. However, when fully dried and mixed, the concentrations of carbon varied markedly. Factors affecting final concentrations included the additive's ability to bond to the silica, its volatility, and its molecular fraction of carbon. For example, although the preservative paraffin is rich in carbon, the contaminant had largely evaporated from the substrate before measurement. An average concentration for each stock is given in Table 1 under the heading Carbon adhesion. 
Table 1 The results of the pretreatment of the stocks of preservatives, glues and adhesives. Carbon adhesion relates to the initial carbon concentration, as measured on 10-mg samples of contaminated stock. The amounts remaining after standard and specialized treatments are given as percentages of this initial value.

\begin{tabular}{|c|c|c|c|c|c|}
\hline Additive & $\begin{array}{l}\text { Age } \\
\left({ }^{14} \mathrm{C} \text { yr BP }\right)\end{array}$ & $\begin{array}{l}\text { Carbon adhesion } \\
(\mathrm{ppm})\end{array}$ & $\begin{array}{l}\text { Carbon remaining } \\
\text { after standard } \\
\text { treatment }\end{array}$ & $\begin{array}{l}\text { Most successful } \\
\text { specialized } \\
\text { treatment }\end{array}$ & $\begin{array}{l}\text { Carbon remaining } \\
\text { after specialized } \\
\text { treatment }\end{array}$ \\
\hline $\begin{array}{l}\text { Adhesives } \\
\text { Common resin } \\
\text { (UHU) }\end{array}$ & $18,000^{\mathrm{a}}$ & $68,000 \pm 1300$ & $0.2 \%$ & - & - \\
\hline $\begin{array}{l}\text { (UHU) } \\
\text { Water-soluble } \\
\text { polymer } \\
\text { (PVAc) }\end{array}$ & $>60,000$ & $46,000 \pm 2600$ & $61.3 \%$ & $\begin{array}{l}\mathrm{H}_{2} \mathrm{O} / \text { acetone/ } \\
\mathrm{H}_{2} \mathrm{O} / \text { methanol } \\
\left(45^{\circ} \mathrm{C}, 45 \mathrm{~min}\right)\end{array}$ & $27.2 \%$ \\
\hline $\begin{array}{l}\text { Cyanoacrylate } \\
\text { (superglue) }\end{array}$ & Unknown & $177,000 \pm 14,000$ & $1.5 \%$ & (Standard) & $1.5 \%$ \\
\hline $\begin{array}{l}\text { Epoxy resin } \\
\text { (araldite) }\end{array}$ & $6000^{*}$ & $198,000 \pm 16,000$ & $99.6 \%$ & $\begin{array}{l}\text { Sodium ethoxide } \\
\text { (RT, } 48 \mathrm{hr} \text { ) }\end{array}$ & $67.2 \%$ \\
\hline $\begin{array}{l}\text { Glues } \\
\text { Methylcellulose } \\
\text { (paper paste) }\end{array}$ & Modern & $5600 \pm 500$ & $83.5 \%$ & $\begin{array}{l}\mathrm{H}_{2} \mathrm{O} \\
\left(45^{\circ} \mathrm{C}, 60 \mathrm{~min}\right)\end{array}$ & $0.6 \%$ \\
\hline $\begin{array}{l}\text { Collagen } \\
\text { (pearl glue) }\end{array}$ & Modern & $27,000 \pm 400$ & $35.3 \%$ & $\begin{array}{l}\mathrm{H}_{2} \mathrm{O} \\
\left(45^{\circ} \mathrm{C}, 60 \mathrm{~min}\right)\end{array}$ & $5.5 \%$ \\
\hline $\begin{array}{l}\text { Preservatives } \\
\text { Lanolin } \\
\text { Paraffin } \\
\text { Beeswax } \\
\text { Neatesfoot oil } \\
\text { Natural bitumen }\end{array}$ & $\begin{array}{l}\text { Modern } \\
>60,000 \\
\text { Modern } \\
\text { Modern } \\
>60,000\end{array}$ & $\begin{aligned} 230,000 & \pm 20,000 \\
5700 & \pm 750 \\
105,000 & \pm 6000 \\
320,000 & \pm 15,000 \\
200,000 & \pm 8700\end{aligned}$ & $\begin{array}{l}0.0 \% \\
0.0 \% \\
0.3 \% \\
0.2 \% \\
0.70 \%\end{array}$ & $\begin{array}{l}- \\
- \\
\overline{\text { (Standard) }}\end{array}$ & $\begin{array}{l}- \\
- \\
\overline{-} \\
0.70 \%\end{array}$ \\
\hline
\end{tabular}

${ }^{a}$ see Bruhn et al. (2001).

Environmental contamination is generally targeted by the aqueous phases of the pretreatment chemistry. Accordingly, 20-mg quantities of the carbonate and humic acid stocks were subjected to the full ABA treatment described in the "Contamination Accrual" section above. Once again, after each stage 2 tests were removed, freeze-dried, and analyzed for residual carbon content. Anthropogenic contaminants, on the other hand, are usually removed by solvent extraction prior to the ABA treatment. There were 2 stages to the analysis applied to these contaminated stocks. In the first, they were treated as if the additive was unknown; that is, using ORAU's standard solvent wash outlined above (acetone, methanol, and chloroform). If significant contamination still remained, specialized treatments were then employed to target the impurity.

\section{RESULTS AND DISCUSSION}

The levels of contamination accrued on the pure Chromosorb substrate are given in Figure 2a. The dotted line represents the Chromosorb blank: the average quantity of carbon detected on $10 \mathrm{mg}$ of pristine material $(\sim 4 \mu \mathrm{g})$. The remaining data show the average of the 2 measurements taken after each of the phases indicated. The concentrations are expressed in parts per million (ppm) by weight, as the carbon was in particulate form adhered to a solid substrate. No significant residual contamination was detected on the pure Chromosorb after any of the solvent washes, or the initial acid wash. As expected, significant amounts were accrued during the base phase; however, such carbonaceous species must have remained mobile as they were readily removed by the following rinses to neutrality and ultimately by the final acid phase. Furthermore, no significant differences were noted in the contamination peak when the concentration of $\mathrm{NaOH}$ was increased from 0.2 to $1 \mathrm{M}$. 

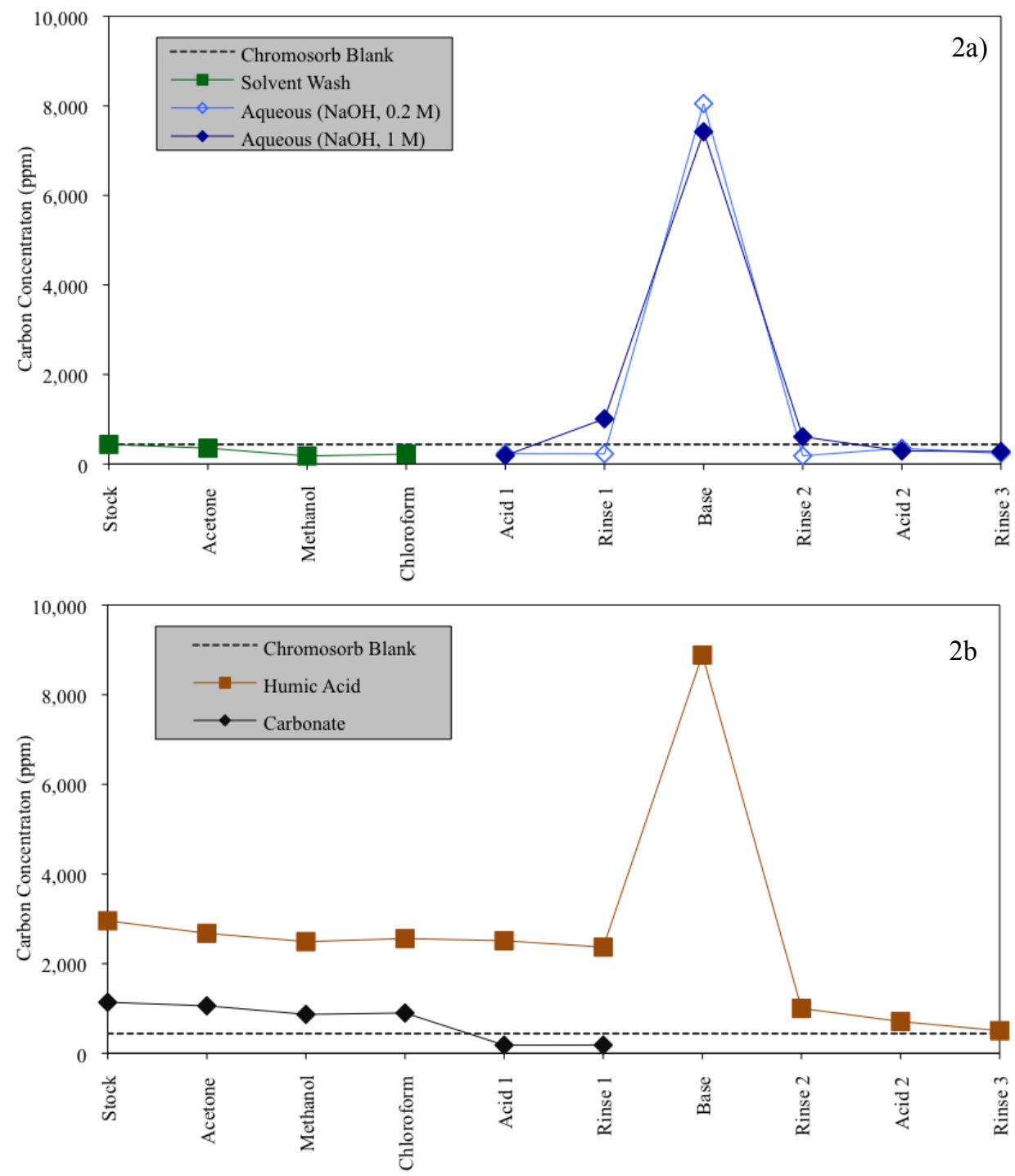

Figure 2 The profile of carbon accumulation on pure Chromosorb samples throughout ${ }^{14} \mathrm{C}$ pretreatment (above); the same chart for the purification of carbonate and humic acid stocks (below).

The contaminant profiles for carbonate and humic acid are presented in Figure $2 \mathrm{~b}$. In the former case, the initial $\mathrm{HCl}$ treatment rapidly eliminated all contamination present. The humic acids persisted until the base treatment, whereupon the peak due to absorbed atmospheric $\mathrm{CO}_{2}$ was again observed. However, the hydroxide phase also dissolved the humic material, and the Chromosorb was returned to background levels once the following water rinses and acid steps had been conducted.

The results of the decontamination of the stocks of preservatives, glues, and adhesives are shown in Table 1. In the main, the preservatives were efficiently removed by ORAU's standard solvent wash for such contaminants (acetone, methanol, and chloroform). The exception was natural bitumen. Although only $0.7 \%$ of its starting concentration remained, in absolute terms this was still signifi- 
cant (approximately $15 \mu \mathrm{g} / 10 \mathrm{mg}$ Chromosorb). Conversely, most of the artificially aged glues and adhesives were impervious to the routine solvent wash. Some improvement was evident when the specialized treatments were employed. The more water-soluble species, such as PVAc and methylcellulose, were more easily removed in aqueous media. For the remaining contaminants, a number of organic solvents were tried, including dichloromethane and toluene, but they generally proved no more effective than the standard acetone, methanol, and chloroform protocol. The epoxy resin proved most difficult to remove, with a limited amount of success obtained by the use of sodium ethoxide. The resilience of the glues and adhesives to such a wide range of treatments emphasizes the importance of avoiding such contamination wherever possible during sampling. Indeed, if PVAc, pearl glue, or epoxy resin are known to be present, due consideration should be given as to whether or not accurate ${ }^{14} \mathrm{C}$ dating is achievable.

\section{CONCLUSIONS}

In this work, the usefulness of the silica material, Chromosorb, was investigated as a means by which carbon contamination during ${ }^{14} \mathrm{C}$ pretreatment could be monitored. By substituting pure Chromosorb for ${ }^{14} \mathrm{C}$ samples, the amount of contamination accrued at various stages of the process could be observed, thereby allowing the effect of subsequent modifications to be examined. Furthermore, Chromosorb provided an excellent non-carbonaceous substrate onto which a range of contaminants could be adhered and their removal closely examined. In this study, many synthetic products proved very difficult to remove, with the exception of common resin adhesive. Traditional glues that utilize natural biopolymers like cellulose and collagen were most effectively removed by soaking in water, although some residual contamination was generally still evident. More success was achieved with common preservatives, which were eliminated by a standard organic solvent wash. The key exception was carbon-rich natural bitumen, where significant levels of contamination still remained.

\section{REFERENCES}

Brock F, Higham TFG, Ditchfield P, Bronk Ramsey C. 2010. Current pretreatment methods for AMs radiocarbon dating at the Oxford Radiocarbon Accelerator Unit (ORAU). Radiocarbon 52(1):103-12.

Bruhn F, Duhr A, Grootes PM, Mintrop A, Nadeau M-J 2001. Chemical removal of conservation substances by 'Soxhlet'-type extraction. Radiocarbon 43(2A): 229-37.

D'Elia M, Gianfrate G, Quarta G, Giotta L, Giancane G, Calcagnile L. 2007. Evaluation of possible contamination sources in the ${ }^{14} \mathrm{C}$ analysis of bone samples by FTIR spectroscopy. Radiocarbon 49(2):201-10.

de Vries H, Barendsen GW. 1954. Measurements of age by the Carbon-14 technique. Nature 174(4442):113841.

Goslar T, Pazdur MF. 1985. Contamination studies on mollusk shell samples. Radiocarbon 27(1):33-42.

Gowlett JAJ. 1987. The archaeology of radiocarbon accelerator dating. Journal of World Prehistory 1(2): $127-70$.
Green JW. 1963. Wood Cellulose. New York: Academic Press.

Green LR, Thickett D. 1995. Testing materials for use in the storage and display of antiquities: a revised methodology. Studies in Conservation 40(3):145-52.

Hoper ST, McCormac FG, Hogg AG, Higham TFG, Head MJ. 1998. Evaluation of wood pretreatments on oak and cedar. Radiocarbon 40(1):45-50.

van Klinken GJ, Hedges REM. 1998. Chemistry strategies for organic ${ }^{14} \mathrm{C}$ samples. Radiocarbon $40(1): 51-$ 6.

Yates T. 1986. Studies of non-marine mollusks for the selection of shell samples for radiocarbon dating. Radiocarbon 28(2A):457-63.

Yizhaq M, Mintz G, Cohen I, Khalaily H, Weiner S, Boaretto E. 2005. Quality controlled radiocarbon dating of bones and charcoal from the Early Pre-Pottery Neolithic B (PPNB) of Motza (Israel). Radiocarbon 47(2):193-206. 